\title{
Application of Neural Networks and Axial Flux for the Detection of Stator and Rotor Faults of an Induction Motor
}

Research Article

\author{
Paweł Ewert
}

Department of Electrical Machines, Drives and Measurements, Wrocław University of Science and

Technology, Wybrzeże Wyspiańskiego 27, 50-370 Wrocław, Poland.

Received July 31, 2018; Accepted September 25, 2018

Abstract: The paper presents the possibility of using neural networks in the detection of stator and rotor electrical faults of induction motors. Fault detection and identification are based on the analysis of symptoms obtained from the fast Fourier transform of the voltage induced by an axial flux in a measurement coil. Neural network teaching and testing were performed in a MATLAB-Simulink environment. The effectiveness of various neural network structures to detect damage, its type (rotor or stator damage) and damage levels (number of rotor bars cracked or stator winding shorted circuits) is presented.

Keywords: Induction motor • Stator and rotor faults • Diagnostics • Axial flux • Neural network

\section{Introduction}

Induction motors are currently widely used in industry due to their simple structure, low price and relatively high reliability. They constitute about $90 \%$ of all electrical machines used in different individual drive systems and drives used in production lines (Orłowska-Kowalska and Dybkowski, 2016). Manufacturers try to make the largest number of products on their production lines in a relatively short time. Undesired downtime in a production process, even if very short, generates substantial losses, sometimes exceeding the costs of installing a system that can possibly prevent a machine from a serious fault. Therefore, the use of modern fault monitoring and diagnostic systems allowing the detection of faults at early stages is very important nowadays (Henao et al., 2014).

The most frequent electrical faults of induction motors include stator winding short circuits and broken rotor bars of a squirrel-cage rotor. If faults are detected at an early stage, it is possible to plan overhauls and, as a result, limit production line downtime costs. It seems that the detection of single shorted turns occurring in stator windings is especially important due to the fact that they are strongly destructive and can lead to serious faults in a short time (Wolkiewicz et al., 2015). The most frequently used diagnostic methods of induction motors are based on the spectral analysis of stator currents (Jung et al., 2006). Another non-invasive method used in the diagnostics of induction motor drives is based on the analysis of an axial flux (Bacha et al., 2008; Ceban et al., 2012; Ewert, 2017; Henao et al., 2014; Meshgin-Kelk et al., 2004; Penman et al., 1994; Pietrowski, 2011; Romary et al., 2013; Toni et al., 2007; Tulicki et al., 2016; Vas, 1993; Wolkiewicz and Skowron, 2017). However, the distinction of the electrical fault type is difficult because the fault symptoms visible in stator current or axial flux spectra cannot be easily found. Thus, neural networks, which are currently popular in the fault detection of electrical motors (Bacha et al., 2008; Kowalski and Orlowska-Kowalska, 2003; Morsalin et al., 2014; Pietrowski, 2011; Rama Krishna and Kishan, 2013; Vas, 1999; Wolkiewicz and Kowalski, 2016), have been used in this paper. Currently, the literature discusses the use of neural networks to detect faults in induction motor rotors (Bacha et al., 2008) or stators (Pietrowski, 2011) 
based on symptoms obtained from axial flux analysis. The new approach should be based on development of a neural detector that recognises different types of damages.

The main goal of this paper is the design of neural detectors that can help in the diagnosis of winding faults in the induction motor and will be able to distinguish between the stator inter-turn short circuit fault and a rotor bar damage, based on the fault symptoms obtained through analysis of the axial flux spectrum. The paper presents the results of experimental research conducted on a specially prepared induction motor, with modelled stator and rotor faults, fed directly from the grid. Analysis of the voltage induced in a measurement coil by the axial flux is used to monitor the type and level of a fault. These fault symptoms, after suitable pre-processing, have been used for training the neural fault detectors, and the results obtained for different neuron detector structures are presented. The symptoms obtained from the spectral analysis of a voltage induced in a measurement coil were used as the neural network inputs. The taught neural networks were used to detect the technical condition of the induction motor and for assessment of the type and degree of the damage.

\section{Electrical faults}

\subsection{Axial flux measurement}

The axial flux in an ideal electrical machine should equal zero. In reality, such a situation will never take place because there always are some asymmetries in the rotor and stator circuits, caused by e.g. non-ideal geometry, heterogeneity of the used materials or small errors made at the production stage. The occurrence of these asymmetries, as well as asymmetries caused by the motor winding faults, results in an axial flux, which can be measured using properly installed measurement coils. The axial flux distribution in an induction motor and the possible distribution of measurement coils are presented in Fig. 1.

The measurements of the axial flux can be non-invasive (using coils distributed on a machine body) or invasive (a coil placed inside a machine). The occurrence of a fault in a stator or rotor leads to the asymmetry of a given circuit, with a resultant increase in the value of the axial flux (Bacha et al., 2008; Ewert, 2017; Wolkiewicz and Skowron, 2017). The application of an axial flux in the detection of stator faults has been described in the literature previously (Penman et al., 1994; Vas, 1993; Wolkiewicz and Skowron, 2017). In this paper also, rotor faults are determined based on this measurement. Accurate analysis of the harmonics occurring in the axial flux is used to identify particular faults.

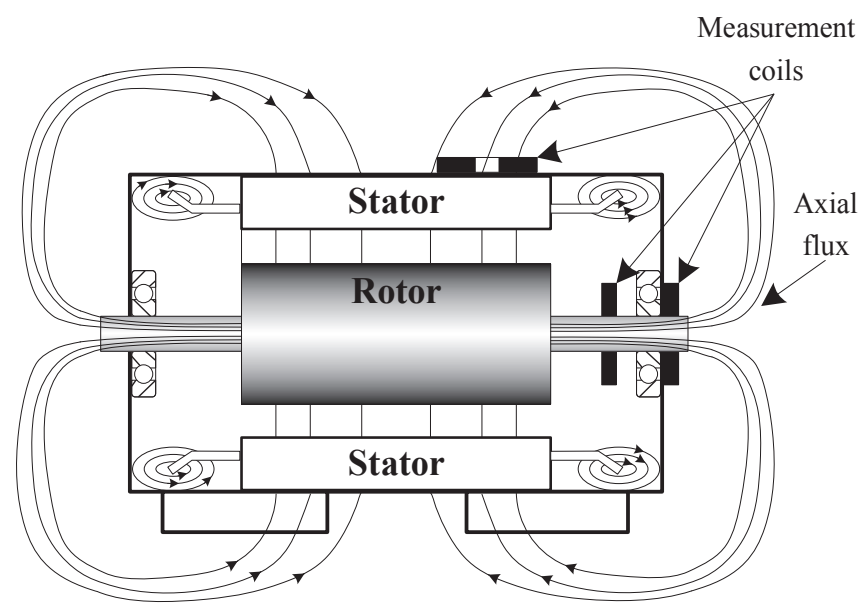

Fig. 1. Axial flux distribution in an induction motor with asymmetries and possible placement of measurement coils (Source: Ceban et al., 2012; Ewert, 2017; Henao et al., 2014; Romary et al., 2013)

\subsection{Symptoms of stator winding faults in an axial flux}

According to the literature, stator winding faults are the most common electrical faults of induction motors and make up about $38 \%$ of all faults (Morsalin et al., 2014; Wolkiewicz et al., 2015). The basic faults occurring in the stator of an induction motor are as follows (Morsalin et al., 2014; Wolkiewicz et al., 2015): 
1. Short circuits between turns in a coil,

2. Coil-to-coil short circuits in one phase,

3. Phase-to-phase short circuits,

4. Phase-to-ground short circuit, and

5. Open phase.

Recently, research is oriented towards the early detection of short circuits between single turns in a coil, because this type of fault spreads out very quickly and is a source of the other stator winding faults mentioned earlier. Such a fault is not detected by currently used security systems, although the current flowing in one short circuit is sometimes several dozen times bigger than the nominal current. Such a large current is very destructive. It results in a quick increase in temperature in a shorted circuit and, in consequence, leads to the destruction of insulation and the spread of the fault. Unfortunately, the time interval between the occurrence of the short circuit between single turns and the inter-phase or phase-to-ground short circuits is not known. This is why diagnostic methods allowing for the early detection of the short circuit are very important.

Literature analysis shows that it is possible to detect stator winding faults on the basis of the spectral analysis of an axial flux. The characteristic harmonics of the flux spectrum are described by the following formula (Ewert, 2017; Toni et al., 2007; Wolkiewicz and Skowron, 2017):

$$
f_{s d}=\left|k f_{0} \pm l \frac{1-s}{p_{b}} f_{0}\right|=\left|k f_{0} \pm l f_{m}\right|
$$

where:

$f_{0}$ - supply voltage frequency $[\mathrm{Hz}]$,

$f_{m}$ - rotational frequency [Hz],

$k$ - order of the time harmonic of supply frequency, $k=1,3,5, \ldots$,

$l=1,2,3, \ldots, 2 \mathrm{p}_{b}-1$,

$p_{b}$ - number of pole pairs, and

$s-$ slip.

Table 1 presents the frequencies in the spectrum of the axial flux at the moment of the occurrence of a stator winding short circuit. According to (Wolkiewicz and Skowron, 2017) the distinguished components usually show the biggest amplitude changes and, from the point of view of diagnostics are of significant importance.

The detection of winding short circuits is most often non-invasive - a coil is located on a machine body, as illustrated in Fig. 1. Monitoring the state of windings is based on the spectral analysis of the voltage induced in a measurement coil.

Table 1. Presentation of harmonics in an axial flux informing about the occurrence of a winding short circuit in a motor with two pole pairs

\begin{tabular}{|c|c|c|c|c|c|c|}
\hline \multirow[t]{3}{*}{$l$} & \multicolumn{6}{|c|}{$k$} \\
\hline & \multicolumn{2}{|c|}{1} & \multicolumn{2}{|c|}{3} & \multicolumn{2}{|c|}{5} \\
\hline & - & + & - & + & - & + \\
\hline 1 & $f_{0}-f_{m}$ & $f_{0}+f_{m}$ & $3 f_{0}-f_{m}$ & $3 f_{0}+f_{m}$ & $5 f_{0}-f_{m}$ & $5 f_{0}+f_{m}$ \\
\hline 2 & $f_{0}-2 f_{m}$ & $f_{0}+2 f_{m}$ & $3 f_{0}-2 f_{m}$ & $3 f_{0}+2 f_{m}$ & $5 f_{0}-2 f_{m}$ & $5 f_{0}+2 f_{m}$ \\
\hline 3 & $f_{0}-3 f_{m}$ & $f_{0}+3 f_{m}$ & $3 f_{0}-3 f_{m}$ & $3 f_{0}+3 f_{m}$ & $5 f_{0}-3 f_{m}$ & $5 f_{0}+3 f_{n}$ \\
\hline
\end{tabular}

\subsection{Symptoms of squirrel-cage rotor faults in an axial flux}

In technical literature, squirrel-cage rotor faults are reported to constitute nearly $10 \%$ of all induction motor faults (Kowalski and Orlowska-Kowalska, 2003; Meshgin-Kelk et al., 2004; Morsalin et al., 2014). In the case of $\approx 100 \mathrm{~kW}$ induction motors made with a die-cast aluminium cage, the need to diagnose faults is minimal. Faults hardly ever occur in such rotors and, if they do, they take place during the production process. In the case of higher-power motors or special solutions with a copper cage and a hard solder connection between bars and end rings, faults are more common. These faults are caused by clearance between the bars and slots, which makes heat exchange between bars and steel laminations more difficult and, in consequence, may lead to their deformation. 
As a result of cracks in the rotor cage, current and magnetic asymmetry arise in the stator and rotor circuits, resulting in a non-uniform magnetic pull between the stator and the rotor. As a consequence, bearing loads may be increased, and in extreme cases, a seizure between a rotor and a stator may occur. Unsymmetry of currents is characterised by slip frequencies occurring in the axial flux spectrum. For this purpose, the analysed spectrum is used to search for frequency of harmonic components described by the following equations (Ewert, 2017; Tulicki et al., 2016; Vas, 1993):

$$
\begin{aligned}
& f_{r d 1}=s f_{0}, \\
& f_{r d 2}=f_{0}[s+a(1-s)],
\end{aligned}
$$

where $a=3,5,7, \ldots$

As a result of the occurrence of speed oscillation caused by the faults of the squirrel-cage rotor bars, the spectrum can show the following components (Ceban et al., 2012; Ewert, 2017; Meshgin-Kelk et al., 2004; Romary et al., 2013; Tulicki et al., 2016):

$$
f_{r d 3}=a s f_{0} .
$$

Monitoring of the state of a squirrel-cage rotor can be conducted simultaneously with the monitoring of the state of stator windings. Both faults are characterised by different symptoms appearing in the axial flux, as well as in the voltage induced in the measurement coil.

\section{Neural detectors of electrical faults}

The neural detectors are designed for monitoring and diagnosing the described stator or rotor faults in the induction motor supplied from a grid. The proposed detectors are based on the most frequently used unidirectional neuron architecture, also defined in literature as 'multi-layer perceptron' (MLP; Bacha et al., 2008; Kowalski and OrlowskaKowalska, 2003; Morsalin et al., 2014; Rama Krishna and Kishan, 2013; Vas, 1999; Wolkiewicz and Kowalski, 2016). The MLP network structure includes neurons connected with each other and grouped into layers (input and output layers, as well as hidden layers that do not have any direct connection with external signals). In addition to this, there are no connections between neurons in the same layer. Activation functions of input and output neurons are linear, while in the hidden layers, the hyperbolic tangent was used. In Fig. 2 and Fig. 3, two different neural structures are presented, regarding the objective of the network. The neural network with only one output, shown

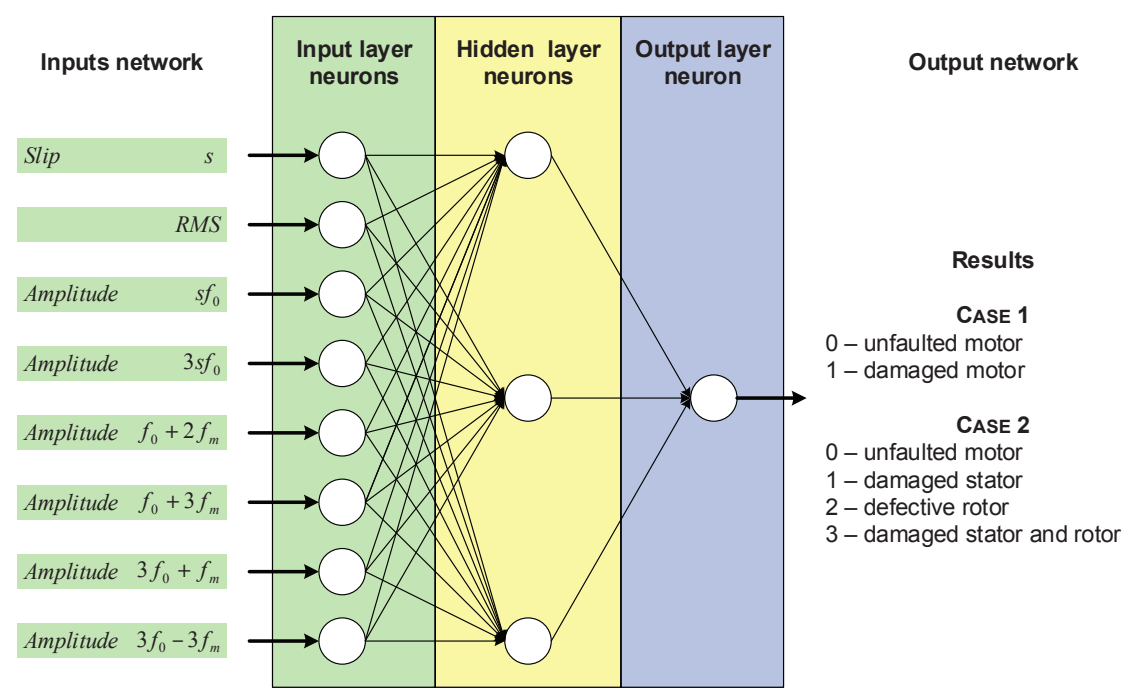

Fig. 2. Sample structure of neural network with one neuron in the output layer 
in Fig. 2, can be used in two cases: Case 1 - the distinction between undamaged and damaged motors; Case 2 distinction between the conditions of undamaged motor, damaged stator case, faulted rotor case or both faulted stator and rotor windings. The second network presented in Fig. 3 is designed for the diagnosis of the damage type or level. Both neural detectors with different structures have been trained using the same type of fault symptoms. They are described in detail in the following sections.

The output signal of a particular neuron in the MLP network is given by the following equation:

$$
\begin{aligned}
& y_{j}=f\left(\sum_{i=1}^{N} w_{i j} x_{i}(t)+w_{0 j}\right) \\
& f(u)=\operatorname{tgh}(\beta u),
\end{aligned}
$$

where $f$ - activation function, $w_{i j}$ - weighting factors, $x_{i}$ - input signals, $\beta$-correction factor for the shape of the activation function, $u$ - activation function argument and $w_{0 j}$ - bias value.

The values of the weighted connection coefficients were trained using the Levenberg-Marquardt algorithm (Morsalin et al., 2014; Vas, 1999).

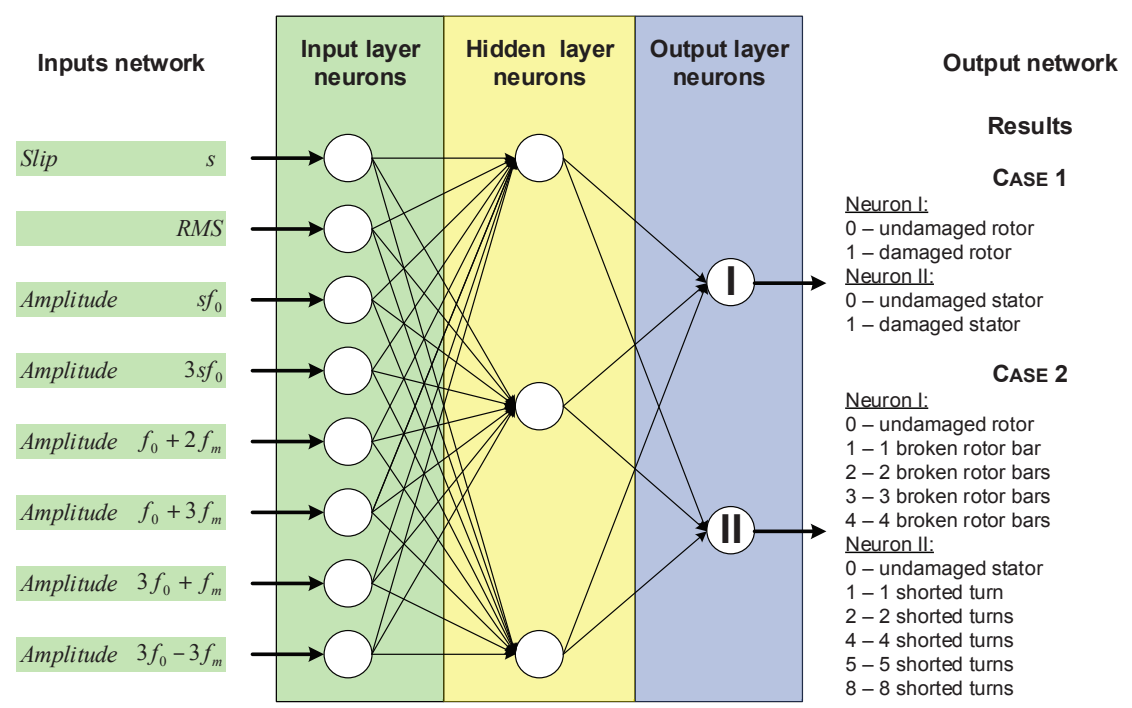

Fig. 3. Sample structure of neural network with two neurons in the output layer

\section{Description of the laboratory setup and fault symptoms measurements}

The experimental research was conducted on a specially prepared small power induction motor, $1.5 \mathrm{~kW}, \mathrm{Sh}-90 \mathrm{~L}-4$ type, coupled with a DC motor (1.5 kW, PZB b44b type), generating a load torque. The induction motor is supplied directly from the grid. The specially prepared stator winding allowed to conduct the controlled short circuits of a selected number of turns at each stator phase. This article presents the results obtained for the short circuit of maximum eight turns in phase $A$, while the total number of turns is equal to 312 . Rotor faults were modelled by physical reaming of selected bars. The weight loss was compensated by a resin mixture to prevent imbalance. The article presents the results obtained for maximum four faulted bars, while the total number of bars is equal to 26 . The measurement coil used for the purpose of the research was made of 600 turns, and the wire diameter was $0.7 \mathrm{~mm}^{2}$; it was placed on the bearing cover. A picture of the laboratory test stand is presented in Fig. 4.

The acquisition of measurement data and the signal analysis were conducted using a personal computer (PC) equipped with a NI USB-9234 measurement card. The diagnostic signal was measured at 2,048 $\mathrm{Hz}$ frequency for 10 seconds. The research application for signal pre-processing was created in the LabView 2016 environment. 


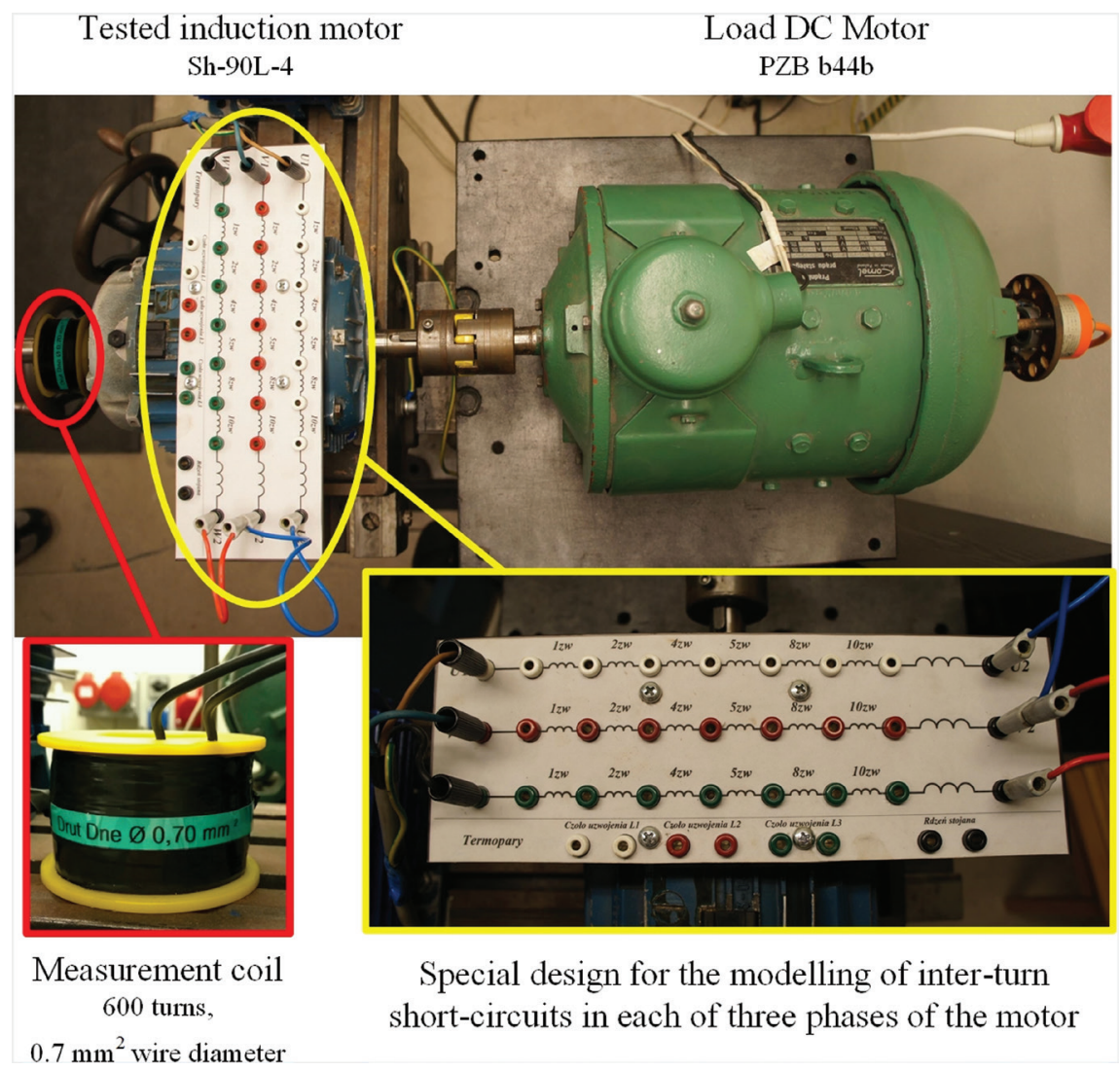

Fig. 4. Laboratory test stand

The experimental research was focussed on the analysis of the voltage induced by the axial flux in a measurement coil. The detection of stator faults can be conducted on the basis of the analysis of the spectrum and the root mean square (RMS) value of this voltage. In Fig. 5 are shown the spectra of the motor running under nominal load without any faults, as well as with the following conditions: with eight shorted turns in phase A; with four broken rotor bars; and also with simultaneous stator (eight shorted turns) and rotor (four faulted bars) faults. The presented spectra are shown in the range up to $250 \mathrm{~Hz}$. The arrows on the spectra mark the characteristic fault frequencies. The logarithmic value $[\mathrm{dB}]$ of the induced voltage is obtained using the following formula:

$$
U[d B]=20 \log _{10}\left(\frac{U_{R M S}}{U_{r e f}}\right),
$$

where $U_{\text {ref }}$ is a reference value equal to $1 \mathrm{~V}$.

\section{Results of the study of neural detectors}

\subsection{Description of the inputs of neural detectors}

Based on the analysis of laboratory tests, the symptoms of damage to the rotor cage and stator windings were selected. The design of neural detectors was performed in a MatLab-Simulink environment. The following inputs of the neural network are introduced:

- slip value $s$ (informing about the motor load),

- effective value of the induced voltage in the measurement coil (RMS), 
a)

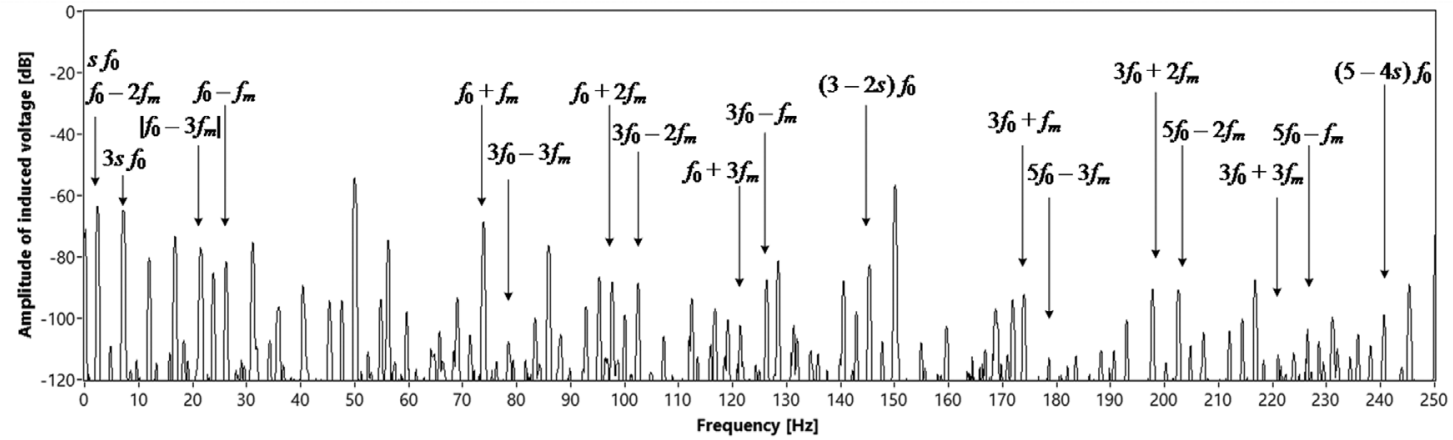

b)

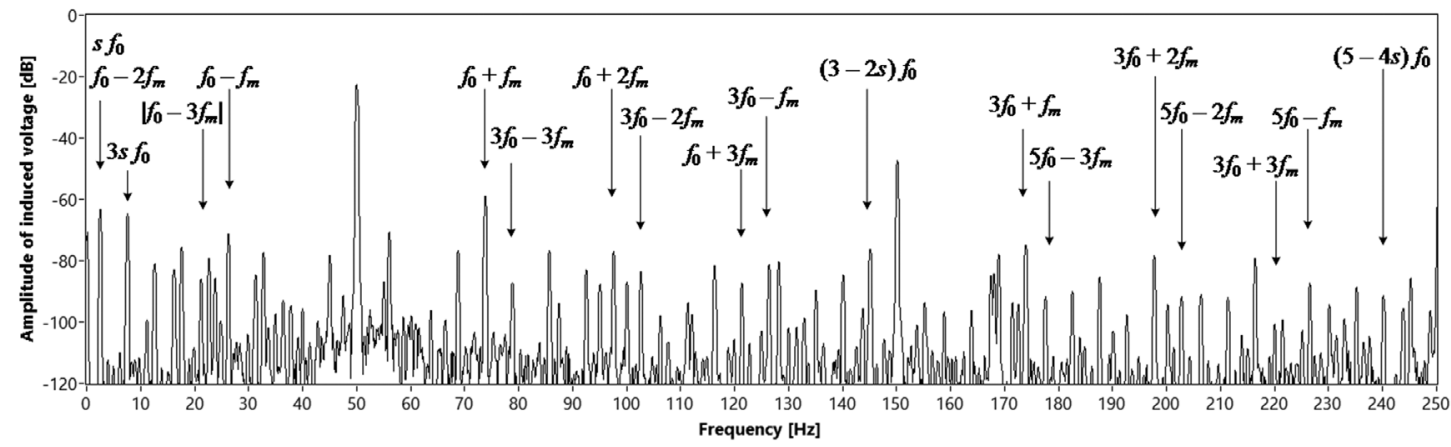

c)

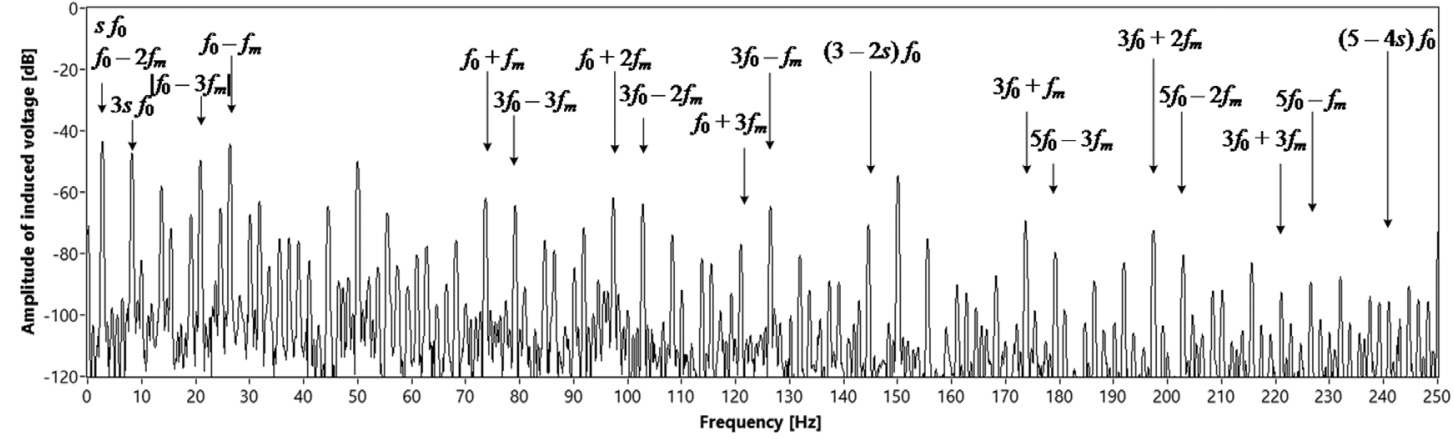

d)

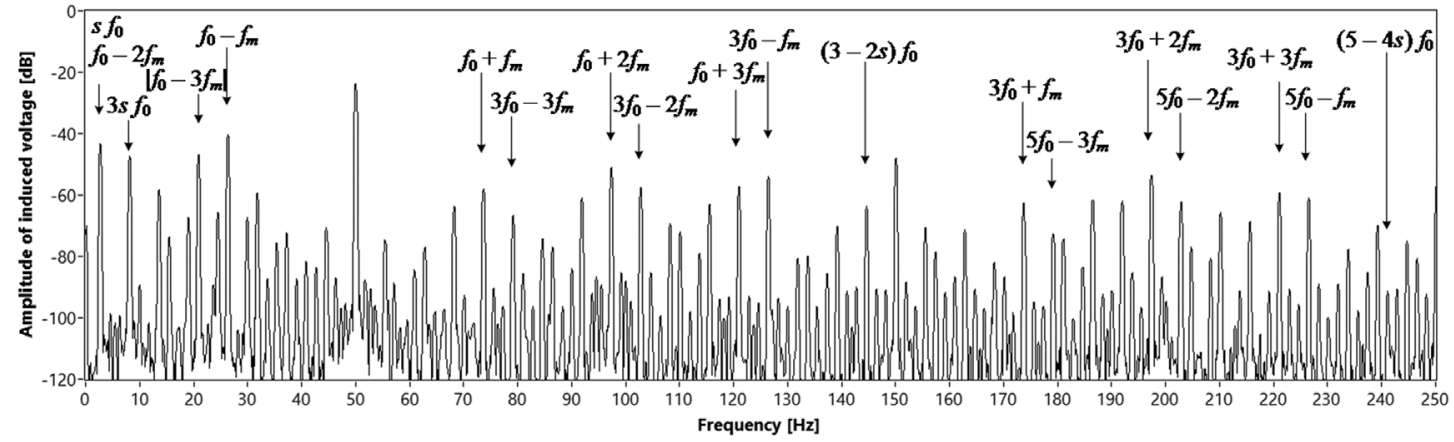

Fig. 5. Spectra of the motor running under nominal load: a) unfaulty motor; b) eight shorted turns in phase $A$; c) four faulty rotor bars; d) four faulty rotor bars and eight shorted turns in phase A

- amplitudes of the characteristic for rotor damage frequencies $\left(s f_{0}\right.$ and $\left.3 s f_{0}\right)$,

- amplitudes of the characteristic for stator damage frequencies $\left(f_{0}+2 f_{m}, f_{0}+3 f_{m}, 3 f_{0}+f_{m}\right.$ and $\left.3 f_{0}-3 f_{m}\right)$.

Amplitudes of characteristic frequencies were obtained from the spectral analysis of a voltage induced in a measurement coil. The paper presents the results obtained for different structures of neural networks, with 
both one and two hidden layers, as well as with one or two neurons in the output layer. The neural network was taught to detect the occurrence of damage, as well as the type or level of damage. During the experimental research, 327 measurements were made, from which the obtained symptoms were divided into two vectors: teaching vector (201 measurements) and test vector (126 measurements). The measurements included the following: undamaged motor, damaged rotor (from one to four broken bars) and damaged stator (one, two, four, five and eight shorted turns). In addition, measurements were made at different load levels (from 0 to $1.2 M_{N}$ ). Tests for the undamaged motor and for the one and two broken rotor bars included 10 load levels, while the tests for three and four broken rotor bars included three load levels $\left(0,0.6 M_{N}\right.$ and $\left.M_{N}\right)$. Stator damage was tested for each rotor used, as well as for the three load levels $\left(0,0.6 M_{N}\right.$ and $\left.M_{N}\right)$. Measurements were made with various numbers of measurement series (from two to six). Symptoms from one measurement series created a test vector, whereas a training vector was created from the remaining measurement series. The network learning parameters are as follows:

- activation function: hyperbolic tangent,

- learning method: Levenberg-Marquardt,

- the maximum number of epochs: 2,000,

- performance goal (mean squared error): $10^{-5}$.

In order to average the performance of tested neural network structures, 30 series of teaching and testing were conducted. The results are summarised in Tables $2-7$. The effectiveness of a neural detector $\left(\eta_{N D}\right)$ or a single neuron from the output layer $\left(\eta_{N D}{ }^{\mathrm{I}}\right.$ or $\left.\eta_{N D}{ }^{\mathrm{II}}\right)$ is defined as follows:

$$
\eta_{N D}=\frac{\operatorname{nnz}\left(\text { round }(y)=y_{0}\right)}{\text { length }(y)} \cdot 100 \%,
$$

where:

$y$ - neural network output vector,

$y_{0}-$ expected result,

nnz ( ) - number of non-zero elements,

round ( ) - value rounded to the integer,

length ( ) - length of vector.

The efficiency of a neural detector with two neurons in the output layer $\left(\eta_{N D}{ }^{\mathrm{I}}\right.$-II $)$ requires a transition from a binary form (each neuron is a single bit) to a decimal form and is defined as follows:

$$
\eta_{N D}^{\mathrm{I}-\mathrm{II}}=\frac{\operatorname{nnz}\left(\operatorname{round}\left(y^{\mathrm{I}}\right) \cdot 2^{0}+\operatorname{round}\left(y^{\mathrm{II}}\right) \cdot 2^{1}=y_{0}^{\mathrm{I}} \cdot 2^{0}+y_{0}^{\mathrm{II}} \cdot 2^{1}\right)}{\text { length }(y)} \cdot 100 \%,
$$

where:

$y^{\mathrm{I}}-$ value at the output of Neuron I in the output layer,

$y^{\text {II }}$ - value at the output of Neuron II in the output layer,

$y_{0}{ }^{\mathrm{I}}-$ expected value at the output of Neuron I in the output layer,

$y_{0}{ }^{\text {II }}-$ expected value at the output of Neuron II in the output layer.

\subsection{Assessment of the technical condition of the machine}

To evaluate the technical condition of the motor, a neural network with one output neuron was built. At the output of the neural network, only two types of information were obtained: undamaged motor - value 0 at the output of the network; or damaged motor - value 1 at the output of the network. Several network structures with one hidden layer have been developed. The test results of these neural networks are presented in Table 2. 
Table 2. Effectiveness of detection of damage in induction motor by neural networks with one hidden layer

\begin{tabular}{lrrrr}
\hline \multirow{2}{*}{ Effectiveness of 30 learning and testing series, \% } & \multicolumn{4}{c}{ Neural network structure } \\
\cline { 2 - 5 } & $8-3-1$ & $8-5-1$ & $8-7-1$ & $8-9-1$ \\
\hline \hline Lowest & 89.7 & 92.9 & 88.9 & 91.3 \\
Highest & 100.0 & 100.0 & 100.0 & 100.0 \\
Average & 97.8 & 97.6 & 97.3 & 96.5 \\
\hline
\end{tabular}

Table 2 shows that the examined structures of neural networks are very effective at evaluating the technical condition of the machine. The average efficiency of tested detectors is about $96 \%-98 \%$. It can be assumed that the network 8-3-1 or 8-5-1 is sufficient for this task.

\subsection{Evaluation of the type of damaged element}

In this case, the output of the neural network with one output neuron returns four values: 0 - undamaged motor, 1 - damaged stator, 2 - defective rotor, 3 - damaged stator and rotor. Networks with one (Table 3) and two (Table 4) hidden layers were used to detect the type of damage.

Table 3. Effectiveness of detection of electrical faults in an induction motor by neural networks with one hidden layer

\begin{tabular}{lccccccc}
\hline \multirow{2}{*}{ Effectiveness of 30 learning and testing series, \% } & \multicolumn{7}{c}{ Neural network structure } \\
\cline { 2 - 8 } & $8-3-1$ & $8-5-1$ & $8-7-1$ & $8-9-1$ & $8-11-1$ & $8-13-1$ & $8-15-1$ \\
\hline \hline Lowest & 26.2 & 67.5 & 76.2 & 73.0 & 65.9 & 65.9 & 76.2 \\
Highest & 88.1 & 89.7 & 91.3 & 93.7 & 95.2 & 93.7 & 93.7 \\
Average & 74.5 & 82.0 & 85.1 & 84.9 & 85.4 & 85.8 & 86.8 \\
\hline
\end{tabular}

Table 4. Effectiveness of detection of electrical faults in an induction motor by neural networks with two hidden layers

\begin{tabular}{lcccccc}
\hline \multirow{2}{*}{ Effectiveness of 30 learning and testing series, \% } & \multicolumn{5}{c}{ Neural network structure } \\
\cline { 2 - 7 } & $8-5-3-1$ & $8-7-5-1$ & $8-9-7-1$ & $8-11-9-1$ & $8-13-11-1$ & $8-15-13-1$ \\
\hline \hline Lowest & 26.2 & 37.3 & 73.8 & 78.6 & 59.5 & 68.3 \\
Highest & 96.8 & 97.6 & 97.6 & 99.2 & 98.4 & 98.4 \\
Average & 81.0 & 84.9 & 88.3 & 91.6 & 88.8 & 92.3 \\
\hline
\end{tabular}

The average efficiency of neural detectors with one hidden layer oscillates around $85 \%$. The lowest average effectiveness was obtained for the network of 8-3-1 structure. Hence, we arrive at the conclusion that three neurons in the hidden layer is too low a value to accomplish this task. Network 8-7-1 seems to be the best solution because the minimum efficiency achieved in the 30 tests was about $76 \%$. Similar results were obtained for the $8-15-1$ network, which has eight neurons more in the hidden layer. Usage of neuron detectors with two hidden layers (Table 5) improves the average detection rate by only a few percentages.

Another approach proposed in this research is to use neural networks with two neurons in the output layer (Fig. 3). In this structure, Neuron I informs about the rotor damage, while Neuron II informs about the stator damage. At the output of each neuron, two values are obtained: 0 - undamaged element or 1 - damaged element. Table 5 summarises the results of the tested neural networks with different numbers of hidden neurons.

The results show that Neuron II - informing about the stator damage - obtained a few percentages higher average effectiveness compared to Neuron I. In the case of both neurons, the average efficiency of the 30 tests oscillates around $93 \%-98 \%$. The average efficiency of the entire neural network described by the relationship expressed in Eq. (9) is also high and ranges from about $91 \%$ for the $8-3-2$ network to about $94 \%$ for the network of 8-11-2 structure. 
Table 5. Effectiveness of detection of electrical faults in induction motor by neural networks with one hidden layer and two neurons in the output layer

\begin{tabular}{|c|c|c|c|c|c|c|c|c|c|c|}
\hline \multirow[t]{3}{*}{ Effectiveness of 30 learning and testing series, $\%$} & \multicolumn{10}{|c|}{ Neural network structure } \\
\hline & \multicolumn{2}{|c|}{ 8-3-2 } & \multicolumn{2}{|c|}{$8-5-2$} & \multicolumn{2}{|c|}{ 8-7-2 } & \multicolumn{2}{|c|}{$8-9-2$} & \multicolumn{2}{|c|}{$8-11-2$} \\
\hline & I & $\|$ & I & ॥ & I & ॥ & I & $\|$ & I & ॥ \\
\hline Lowest & 77.8 & 92.9 & 90.5 & 92.1 & 88.9 & 94.4 & 91.3 & 92.1 & 91.3 & 90.5 \\
\hline Highest & 97.6 & 99.2 & 98.4 & 99.2 & 99.2 & 99.2 & 99.2 & 100.0 & 98.4 & 100.0 \\
\hline Average & 92.8 & 97.7 & 95.1 & 97.1 & 95.2 & 97.4 & 95.9 & 96.8 & 96.2 & 97.3 \\
\hline Lowest & \multicolumn{2}{|c|}{76.2} & \multicolumn{2}{|c|}{88.1} & \multicolumn{2}{|c|}{87.3} & \multicolumn{2}{|c|}{87.3} & \multicolumn{2}{|c|}{86.5} \\
\hline Highest & \multicolumn{2}{|c|}{96.8} & \multicolumn{2}{|c|}{96.8} & \multicolumn{2}{|c|}{98.4} & \multicolumn{2}{|c|}{98.4} & \multicolumn{2}{|c|}{97.6} \\
\hline Average & \multicolumn{2}{|c|}{90.9} & \multicolumn{2}{|c|}{93.0} & \multicolumn{2}{|c|}{93.2} & \multicolumn{2}{|c|}{93.3} & \multicolumn{2}{|c|}{94.1} \\
\hline
\end{tabular}

\subsection{Evaluation of the type and degree of damage}

The usefulness of neural networks with two neurons in the output layer for detection of type and degree of damage was also tested. In this case, Neuron I received values from 0 (undamaged rotor) to 4 (four faulted rotor bars), while Neuron II returned values from 0 (undamaged stator) to 8 (eight shorted turns). Table 6 shows the effectiveness of neural networks with one hidden layer, whereas Table 7 concerns the networks with two hidden layers.

Table 6. Effectiveness of detection of type and degree of electrical faults in induction motor by neural networks with one hidden layer and two neurons in the output layer

\begin{tabular}{|c|c|c|c|c|c|c|c|c|c|c|c|c|c|c|}
\hline \multirow{3}{*}{ Effectiveness of 30 learning and testing series, \% } & \multicolumn{14}{|c|}{ Neural network structure } \\
\hline & \multicolumn{2}{|c|}{$8-3-2$} & \multicolumn{2}{|c|}{$8-5-2$} & \multicolumn{2}{|c|}{$8-7-2$} & \multicolumn{2}{|c|}{$8-9-2$} & \multicolumn{2}{|c|}{$8-11-2$} & \multicolumn{2}{|c|}{$8-13-2$} & \multicolumn{2}{|c|}{$8-15-2$} \\
\hline & 1 & $\|$ & 1 & $\|$ & 1 & $\|$ & I & $\|$ & I & $\|$ & I & $\|$ & 1 & $\|$ \\
\hline Lowest & $\stackrel{\sim}{\stackrel{N}{N}}$ & $\stackrel{\infty}{\stackrel{\infty}{\sim}}$ & ㅁ. & $\underset{N}{N}$ & $\begin{array}{l}\hat{\theta} \\
\dot{\theta}\end{array}$ & $\stackrel{\circ}{\Gamma}$ & $\underset{N}{N}$ & $\stackrel{+}{\circ}$ & $\stackrel{+}{\stackrel{r}{r}}$ & $\frac{\hat{\sigma}}{\infty}$ & $\begin{array}{l}0 \\
\stackrel{N}{N}\end{array}$ & $\check{+}_{\dot{\infty}}$ & $\begin{array}{l}\infty \\
\dot{\infty} \\
\infty\end{array}$ & $\stackrel{m}{\infty}$ \\
\hline Highest & $\underset{\infty}{\check{\infty}}$ & ন্ & స్. & $\begin{array}{l}\circ \\
\dot{8}\end{array}$ & $\begin{array}{l}\stackrel{+}{\sigma} \\
\text {. }\end{array}$ & $\begin{array}{l}0 \\
\dot{8}\end{array}$ & $\begin{array}{l}\text { Nִ } \\
\stackrel{\alpha}{ }\end{array}$ & $\begin{array}{l}\stackrel{\sim}{\alpha} \\
\stackrel{\alpha}{ }\end{array}$ & $\begin{array}{l}\infty \\
\dot{\phi} \\
\dot{8}\end{array}$ & 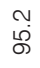 & $\begin{array}{l}\dot{+} \\
\dot{\sigma}\end{array}$ & $\begin{array}{l}\infty \\
\dot{\mathscr{\theta}}\end{array}$ & $\begin{array}{l}0 \\
\text { ó }\end{array}$ & $\tilde{\sigma}$ \\
\hline Average & $\begin{array}{l}0 \\
\stackrel{\emptyset}{0}\end{array}$ & $\bar{\infty}$ & $\stackrel{\Gamma}{\stackrel{N}{N}}$ & $\stackrel{\substack{\infty \\
\infty}}{\infty}$ & $\begin{array}{l}\stackrel{1}{0} \\
\stackrel{\infty}{ }\end{array}$ & $\begin{array}{l}\text { வீ } \\
\text { வ }\end{array}$ & $\underset{\infty}{\stackrel{\infty}{\infty}}$ & $\stackrel{\text { m}}{\text { هं }}$ & ○ & ๓ே & $\begin{array}{l}\circ \\
\text { வ }\end{array}$ & $\stackrel{\stackrel{\sigma}{\sigma}}{\sigma}$ & $\begin{array}{l}\widetilde{N} \\
\tilde{\sigma}\end{array}$ & $\begin{array}{l}\infty \\
\delta \\
\delta\end{array}$ \\
\hline Lowest & \multicolumn{2}{|c|}{22.2} & \multicolumn{2}{|c|}{54.0} & \multicolumn{2}{|c|}{52.4} & \multicolumn{2}{|c|}{61.1} & \multicolumn{2}{|c|}{73.0} & \multicolumn{2}{|c|}{68.3} & \multicolumn{2}{|c|}{78.6} \\
\hline Highest & \multicolumn{2}{|c|}{67.5} & \multicolumn{2}{|c|}{84.1} & \multicolumn{2}{|c|}{89.7} & \multicolumn{2}{|c|}{90.5} & \multicolumn{2}{|c|}{92.1} & \multicolumn{2}{|c|}{91.3} & \multicolumn{2}{|c|}{96.8} \\
\hline Average & \multicolumn{2}{|c|}{55.4} & \multicolumn{2}{|c|}{69.4} & \multicolumn{2}{|c|}{79.8} & \multicolumn{2}{|c|}{81.0} & \multicolumn{2}{|c|}{83.2} & \multicolumn{2}{|c|}{84.9} & \multicolumn{2}{|c|}{87.9} \\
\hline
\end{tabular}

Table 7. Effectiveness of detection of type and degree of electrical faults in induction motor by neural networks with two hidden layers and two neurons in the output layer

\begin{tabular}{|c|c|c|c|c|c|c|c|c|c|c|c|c|}
\hline \multirow{3}{*}{ Effectiveness of 30 learning and testing series\% } & \multicolumn{12}{|c|}{ Neural network structure } \\
\hline & \multicolumn{2}{|c|}{$8-5-3-2$} & \multicolumn{2}{|c|}{$8-7-5-2$} & \multicolumn{2}{|c|}{$8-9-7-2$} & \multicolumn{2}{|c|}{$8-11-9-2$} & \multicolumn{2}{|c|}{$8-13-11-2$} & \multicolumn{2}{|c|}{$8-15-13-2$} \\
\hline & I & $\|$ & I & $\|$ & I & $\|$ & I & $\|$ & 1 & $\|$ & I & $\|$ \\
\hline Lowest & 34.9 & 26.2 & 42.1 & 47.6 & 79.4 & 73.8 & 79.4 & 80.2 & 64.3 & 65.1 & 75.4 & 69.0 \\
\hline Highest & 94.4 & 92.1 & 96.0 & 96.8 & 98.4 & 96.8 & 96.0 & 96.0 & 95.2 & 89.7 & 96.8 & 92.9 \\
\hline Average & 79.1 & 82.3 & 83.8 & 87.3 & 89.8 & 90.5 & 89.8 & 88.4 & 86.0 & 81.7 & 88.5 & 83.0 \\
\hline Lowest & \multicolumn{2}{|c|}{20.6} & \multicolumn{2}{|c|}{28.6} & \multicolumn{2}{|c|}{67.5} & \multicolumn{2}{|c|}{73.8} & \multicolumn{2}{|c|}{51.6} & \multicolumn{2}{|c|}{60.3} \\
\hline Highest & \multicolumn{2}{|c|}{84.1} & \multicolumn{2}{|c|}{91.3} & \multicolumn{2}{|c|}{95.2} & \multicolumn{2}{|c|}{91.3} & \multicolumn{2}{|c|}{88.1} & \multicolumn{2}{|c|}{89.7} \\
\hline Average & \multicolumn{2}{|c|}{69.3} & \multicolumn{2}{|c|}{76.7} & \multicolumn{2}{|c|}{84.5} & \multicolumn{2}{|c|}{84.2} & \multicolumn{2}{|c|}{76.1} & \multicolumn{2}{|c|}{78.6} \\
\hline
\end{tabular}



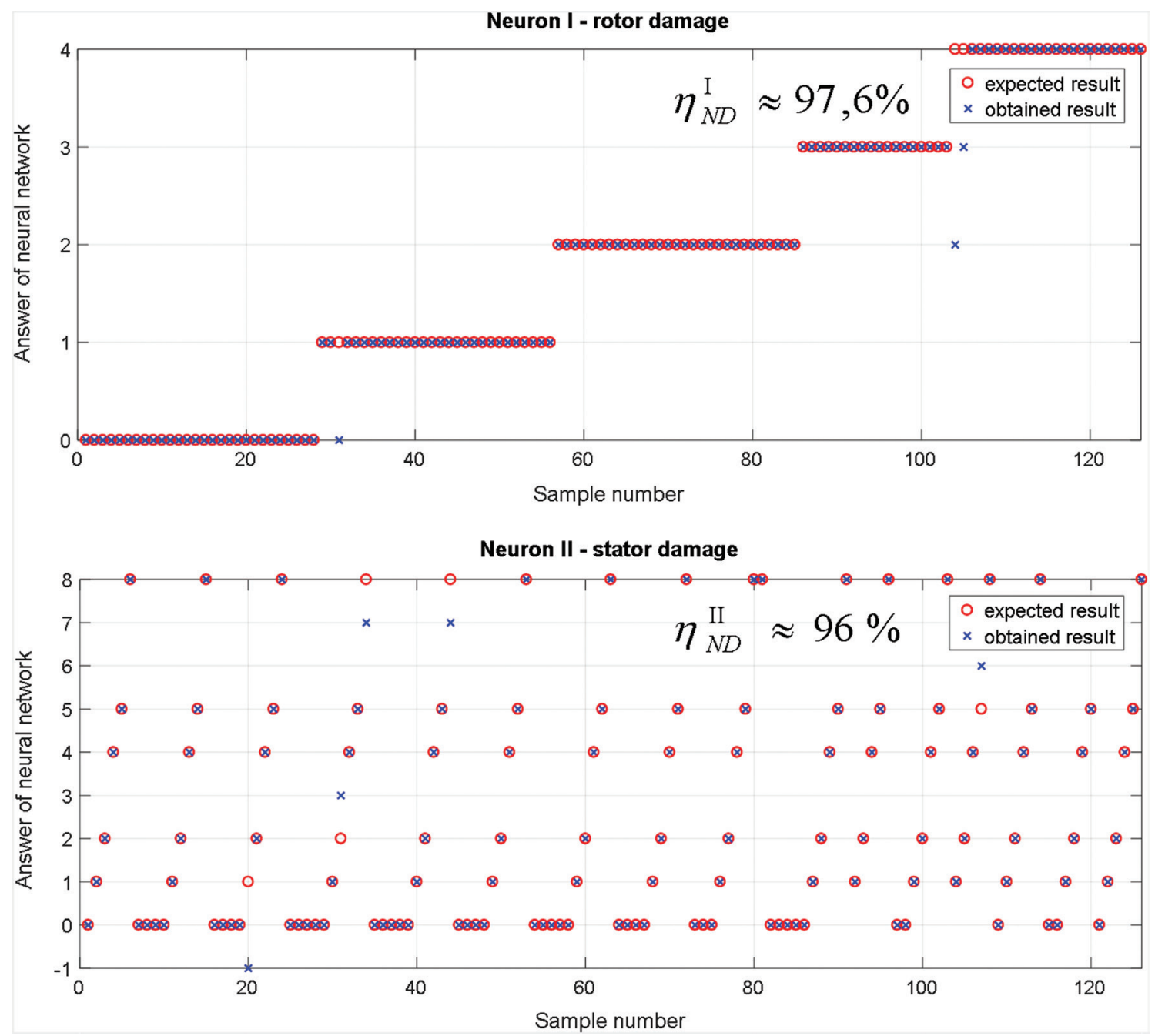

Fig. 6. Sample testing results of $8-15-2$ neural network structure $\left(\eta_{N D}{ }^{\mathrm{I}-\mathrm{II}} \approx 94.4 \%\right)$

A neural network with at least nine neurons in the hidden layer is required to obtain an average detection efficiency of $>80 \%$ for the type and degree of damage. In this case, Neuron II also has a higher average effectiveness. The highest average neural network efficiency of approximately $88 \%$ was obtained for structure $8-15-2$. In Fig. 6 , the sample test results for the neural network with structure 8-15-2 are shown. The use of neural networks with two hidden layers does not affect the efficiency of detection.

The neural network shown in Fig. 6 has a very high efficiency of about 94\%. Effectiveness of individual output neurons is also high, about $97.6 \%$ for Neuron I and about $96 \%$ for Neuron II.

\section{Summary}

On the basis of laboratory tests, it can be stated that the symptoms obtained by the spectral analysis of the voltage induced in the measurement coil by an axial flux enable the diagnosis of electrical damage in induction motors. The use of neural networks automates the process of assessing the technical condition of the tested machine. A relatively simple neural network with one hidden layer and structure 8-3-1 or 8-5-1 can detect electrical damage in induction motor with high efficiency (>95\%). The use of a little bigger network with structure 8-7-1 enables the detection of the 
damage type with an average effectiveness of approximately $85 \%$ using the herein-described 30 tests. Application of networks with two hidden layers increases the effectiveness of detection of the type of damage to a small extent (a few percentages). At the same time, the use of two neurons in the output layer reduces the number of mistakes in determining which electrical circuit of the motor is damaged. A neural network with two neurons in the output layer is able to detect the type and degree of the damage. The highest average efficiency (about $88 \%$ ) of detection of the degree of damage was obtained for the 8-15-2 neural network. In this case, the use of a neural network with two hidden layers also does not improve the performance of the neural detector. The presented research shows that relatively simple MLP-based neural networks with one hidden layer, after proper training procedure, can be effectively applied for different diagnostic tasks, e.g. detection of motor damage, detection of stator or rotor fault, as well as detection of the level of stator fault (number of shorted turns) or rotor fault (number of broken bars).

Supplying the motor from the frequency converter is planned in further research. In this way, it will be possible to check the influence of higher harmonics on the effectiveness of the proposed diagnostic method.

\section{References}

Bacha, K., Henao, H., Gossa, M. and Capolino, G.-A. (2008). Induction Machine Fault Detection Using Stray Flux EMF Measurement and Neural Network-Based Decision. Electric Power Systems Research, 78(7), pp. 1247-1255.

Ceban, A., Pusca, R. and Romary, R. (2012). Study of Rotor Faults in Induction Motors Using External Magnetic Field Analysis. IEEE Transactions on Industrial Electronics, 59(5), pp. 2082-2093.

Ewert, P. (2017). Use of axial flux in the detection of electrical faults in induction motors. In: 2017 International Symposium on Electrical Machines (SME), IEEE, Naleczow, Poland, 18-21 June 2017, pp. 1-6.

Henao, H., Capolino, G.-A., Fernandez-Cabanas, M., Filippetti, F., Bruzzese, C., Strangas, E. and Hedayati-Kia, S. (2014). Trends in Fault Diagnosis for Electrical Machines: A Review of Diagnostic Techniques. IEEE Industrial Electronics Magazine, 8(2), pp. 31-42.

Jung, J. H., Lee, J.-J. and Kwon, B.-H. (2006). Online Diagnosis of Induction Motors Using MCSA. IEEE Transactions on Industrial Electronics, 53(6), pp. 1842-1852.

Kowalski, C. T. and Orlowska-Kowalska, T. (2003). Neural Networks Application for Induction Motor Faults Diagnosis. Mathematics and Computers in Simulation, 63(3-5), pp. 435-448.

Meshgin-Kelk, H., Milimonfared, J. and Toliyat, $H$. A. (2004). Interbar Currents and Axial Fluxes in Healthy and Faulty Induction Motors. IEEE Transactions on Industry Applications, 40(1), pp. 128-134.

Morsalin, S., Mahmud, K., Mohiuddin, H., Halim, M. R. and Saha, P. (2014). Induction motor inter-turn fault detection using heuristic noninvasive approach by artificial neural network with Levenberg

Marquardt algorithm. In: 2014 International Conference on Informatics, Electronics \& Vision (ICIEV). Dhaka, Bangladesh, 23-24 May 2014, pp. 1-6. Available at: https://ieeexplore.ieee.org/ document/7136002.

Orłowska-Kowalska, T. and Dybkowski, M. (2016). Industrial Drive Systems. Current State and Development Trends. Power Electronics and Drives, 1(36)(1), pp. 5-25.

Penman, J., Sedding, H. G., Lloyd, B. A. and Fink, W. T. (1994). Detection and Location of Interturn Short Circuits in the Stator Windings of Operating Motors. IEEE Transactions on Energy Conversion, 9(4), pp. 652-658.

Pietrowski, W. (2011). Application of Radial Basis Neural Network to Diagnostics of Induction Motor Stator Faults Using Axial Flux. Przegląd Elektrotechniczny (Electrical Review), R. 87 NR 6/2011, pp. 190-192.

Rama Krishna, M. S. and Kishan, S. H. (2013). Neural network for the diagnosis of rotor broken faults of induction motors using MCSA. In: 7th International Conference on Intelligent Systems and Control (ISCO), Coimbatore, India, 4-5 January 2013, pp. 133-137. Available at: https://ieeexplore.ieee. org/document/6481136.

Romary, R., Pusca, R., Lecointe, J. P. and Brudny, J. F. (2013). Electrical machines fault diagnosis by stray flux analysis. In: 2013 IEEE Workshop on Electrical Machines Design, Control and Diagnosis (WEMDCD), Paris, France, 11-12 March 2013, pp. 247-256. Available at: https://ieeexplore.ieee. org/document/6525184.

Toni, K., Slobodan, M. and Aleksandar, B. (2007). Detection of turn to turn faults in stator winding with axial magnetic flux in induction motors. In: IEEE International Conference on Electric Machines 
and Drives, Antalya, Turkey, 3-5 May 2007, pp. 826-829. Available at: https://ieeexplore.ieee. org/document/4270748.

Tulicki, J., Petryna, J. and Sułowicz, M. (2016). Fault Diagnosis of Induction Motors in Selected Working Conditions Based on Axial Flux Signals. Technical Transactions, 13(Electrical Engineering, 3-E), pp. 99-113.

Vas, P. (1993). Parameter Estimation, Condition Monitoring, and Diagnosis of Electrical Machines. Oxford: Oxford University Press.

Vas, P. (1999). Artificial Intelligence-Based Electrical Machines and Drives: Applications of Fuzzy, Neural, Fuzzy-Neural and Genetic Algorithm Based Techniques. Oxford: Oxford University Press.
Wolkiewicz, M. and Kowalski, C. T. (2016). Incipient stator fault detector based on neural networks and symmetrical components analysis for induction motor drives. In: 2016 13th Selected Issues of Electrical Engineering and Electronics (WZEE), IEEE, Rzeszow, Poland, 4-8 May 2016, pp. 1-7.

Wolkiewicz, M. and Skowron, M. (2017). Diagnostic system for induction motor stator winding faults based on axial flux. Power Electronics and Drives, 2(37)(2), pp. 137-150.

Wolkiewicz, M., Tarchała, G. and Kowalski, C. T. (2015). Stator Windings Condition Diagnosis of Voltage Inverter-Fed Induction Motor in Open and ClosedLoop Control Structures. Archives of Electrical Engineering, 64(1), pp. 67-79. 